\title{
Inspiration, meaning in life and gratitude as predictors of subjective well-being in the case of a group of students
}

\author{
Beatrice Adriana Balgiu ${ }^{\mathrm{a}^{*}}$, Ruxandra Sfeatcu ${ }^{\mathrm{b}}$ \\ ${ }^{a}$ University Politehnica of Bucharest, Bucharest, România \\ b"Carol Davila” University of Medicine and Pharmacy, Bucharest, România
}

\begin{abstract}
The aim of the present study is to determine the prediction level of gratitude, meaning in life, and inspiration on Subjective Well-being (SWB). 325 undergraduates (149 males and 176 females) with $\mathbf{M}_{\text {age }}=19,29$ (S.D.=1,40) participated in the study. In order to measure the respective concepts, we used the Scale of Positive and Negative Experience (SPANE), the Meaning in Life Questionnaire (MLQ), the Inspiration Scale (IS), and Single-item measures for life satisfaction and gratitude. The study used descriptive, correlational, and regression analyses. The results of the regression analyses showed that gratitude accounts for most of the SWB variance. The presence of meaning affects SWB positively, while the search for meaning is a negative predictor of SWB. Inspiration frequency is one of the weak predictors of SWB, while inspiration intensity is not a significant predictor of SWB. The results are discussed within the context of the existing literature.
\end{abstract}

Keywords: subjective well-being; gratitude; inspiration; meaning in life

\section{Introduction}

Subjective Well-being (SWB) is a complex construct which defines the perception and the assessment of one's own life (life satisfaction, included), alongside the emotional balance between positive and negative emotions (Diener, 2010; Tov, Wirtz, Kushlev et al., 2020). Studies of SWB in association with most of the concepts in positive psychology showed that SWB has various predictors, such as hope and optimism (Rand, Shanahan, Fischer et al., 2020), self-esteem, optimism, and positive affect (Ayyash-Abdo \& Alamuddin, 2008), gratitude (Wood, Froh, \& Geraghty, 2010), gratitude, forgiveness, and humility (Sapmaz, Yıldırım, Topçuoğlu et al., 2016), a superior type of gratitude which includes being content with others, with divinity, with the present moment etc. (Lin, 2014), forgiveness and gratitude Hermaen \& Bhutto, 2020), satisfying the native curiosity (Grigorescu, 2020), meaning in life (Doğana, Sapmaz, Telb et al., 2012; Yuchang, Mingcheng, \& Juny 2016), etc.

The present study aims at analysing the relation between SWB and three of its correlates, gratitude, meaning in life and inspiration, in the case of a group of students.

Gratitude is conceptualized as the feeling of admiration, content, and appreciation of life and of benefits from others (Emmons \& Mishra, 2011). The mechanism of gratitude consists in changing the balance between positive and negative affective experiences, by converting negative experiences into positive ones, which leads to greater life satisfaction (Sun \& Kong, 2013). Research showed the correlation between gratitude and SWB (Emmons \& Mishra, 2011), and other correlates of the latter such as life satisfaction (Xiang \& Youan, 2020). For example, there is a strong positive relationship between gratitude and positive affect, life satisfaction and vitality, and a weak, even negative correlation with negative affect (Kashdan, 2013). Gratitude predicts life

\footnotetext{
*Corresponding author: Beatrice Adriana Balgiu
}

E-mail address: beatrice.balgiu@upb.ro

DOI: $10.51865 /$ JESP.2021.2.10 
satisfaction in the students' case (Salvador-Ferrer, 2017) and life satisfaction, hope and positive affectivity in the case of women (Yoo, 2020). In fact, Robustelli \& Whisman (2018) argues that gratitude is a factor which influences life satisfaction more than personality traits do.

Another concept believed to be related to SWB and to gratitude is meaning in life (ML) (Datu, 2014; Disabato et al., 2017; Ionescu, 2017; Proctor et al., 2010). The concept is defined as the extent to which people believe they have a life purpose (Steger, 2009), it is the significance an individual attaches to the nature of one's being and existence (Steger, Frazier, Oishi et al., 2006). Studies show that meaning in life is a significant predictor of SWB (Damásio \& Koller, 2015; Doğana et al., 2012), of happiness - an affective component of SWB (Kashdan, 2013), and of life satisfaction (Steger, Kashdan, Sullivan et al., 2008). A recent study shows that gratitude and purpose in life predict both independently and jointly the life satisfaction in the case of students. In other words, students who are grateful and have a high sense of their life meaning are happier with their life than those peers who do not feel gratitude or do not have a purpose (Mayungbo \& Ivuoha, 2020).

The two components of meaning in life, the presence of meaning and the search for meaning, have different relations with SWB. Most studies show that the presence of meaning has a positive effect on SWB, while search for meaning is a negative predictor of SWB (Cohen \& Cairns, 2012; Doğana et al., 2012; Galang, Magno, Paterno et al., 2011). One can infer that the presence of meaning results in an increase of well-being, while the search for meaning reduces it. In a similar vein, Park, Park \& Peterson (2010) demonstrate that the search for meaning is related to life satisfaction only when individuals already have a purpose in life. On a different note, upon studying psychosocial well-being in the case of 1300 Argentine adults, Lupano Perugini et al. (2017) found positive correlations between the presence of meaning and emotional and psychosocial well-being and negative correlations between the latter and the search for meaning.

Inspiration was less studied in association with SWB, compared with the other concepts presented. Considered both a state and a trait, inspiration was defined in various ways. Trash and Eliott (2010) conceptualized inspiration as a threefold construct made of transcendence (the awareness of concrete possibilities that are better than the existing ones), evocation (the source of the inspiration comes from beyond the individual self), and motivation (the need to actualize a vision).

Other studies found positive relationships between inspiration, life satisfaction and all six dimensions of psychosocial well-being: autonomy, personal relations, growth, purpose, environmental mastery, and self-acceptance (Schindler, 2014). Several experimental studies highlighted the positive association between positive affect and inspiration (Trash \& Elliott, 2003), and a weak or inexistent association between inspiration and negative effect (Trash, 2007). In addition, it was found that inspiration is positively associated with emotions such as admiration, joy, pride, love, gratitude, and fascination, and negatively associated with sadness and envy, and it does not correlate with fear and shame (Schindler, 2014).

\section{Methodology}

\subsection{Objective}

The study aims to reveal the prediction level of various variables such as inspiration, meaning in life and gratitude on SWB in the case of a group of students. The following hypotheses were constructed:

1: SWB correlates positively with gratitude, presence of meaning, inspiration, and negatively with the search for meaning.

2: SWB variance is accounted for by gratitude, presence, and the search for purpose and inspiration. 


\subsection{Participants}

Three hundred twenty-five undergraduates (149 males and 176 females) in the 18 and 30 age bracket $($ Mage $=19.29$; S.D. $=1.40)$, coming from two domains of study: engineering (69\%) and medicine (31\%) within two public universities from Bucharest (University Politehnica of Bucharest - UPB and respectively University of Medicine and Pharmacy - UMFCD).

\subsection{Instruments}

1. Scale of Positive and Negative Experience - SPANE (Diener et al., 2010) measures positive feelings (Spane-P subscale - 6 items) and negative feelings (Spane$\mathrm{N}$ subscale - 6 items) assessed from 1 - very rarely or never to 5 - very often or always. Spane-Balance is the balance between the positive and the negative emotions and it represents the difference between Spane-P and Spane-N. The score varies between -24 (the lowest score) and 24 (the highest affect balance possible). Most studies report Cronbach $\geq .80$ in the case of both subscales (Diener et al., 2010; Telef, 2015). In the case of this present study - for Spane-P, $\alpha=.86$ and for Spane-N, $\alpha=.82$. CFA highlighted: $\chi^{2} / \mathrm{df}=2.46 ; \mathrm{CFI}=.96 ; \mathrm{RMSEA}=.064 ; \mathrm{SRMR}=.037 ; \mathrm{p}<.001$.

2. Single-item Measure of Life Satisfaction (LS-Si) was established empirically by Jovanović (2016) as an adequate measure of assessment for life satisfaction: "Thinking about your own life and personal circumstances, how satisfied are you with your life as a whole?" with a 11-point scale from 0 - not at all satisfied to 10 - completely satisfied. The convergent validity of this item was proven by studies on adults and high school students where the respective instrument was associated with the Satisfaction with Life Scale - SWLS $(r=.66 ; \mathrm{p}<.001)$. As well as SWLS, the single-item correlates positively with the general well-being and positive affect, it correlates weakly with school success, and negatively with depression, anxiety, stress, and negative affect (Jovanović, 2016).

3. Gratitude Evaluation (GE-Si) consists in the assessment of a single-item regarding gratitude for life: I am grateful for the life I have, on a scale from 1 - strongly disagree to 6 - strongly agree (Proctor et al., 2010). Research has shown that the item correlated positively with life satisfaction $(r=.60)$ assessed by using the Students' Life Satisfaction Scale (Huebner, 1991), positive affect $(\mathrm{r}=.43)$, healthy style $(\mathrm{r}=.36)$ (Adolescent Health Promotion Scale - Chen, Wang, Yang et al., 2003), and negatively, with negative affect $(\mathrm{r}=-.25)$ (PANAS - Watson Clark \& Tellegen, 1988).

4. Meaning in Life Questionnaire - MLQ (Steger et al., 2006) assesses two dimensions of the meaning in life included in the Presence of meaning subscale (5 items) - the extent to which respondents feel that their lives are meaningful, and the Search for meaning subscale (5 items) - the extent to which respondents are engaged and motivated to discover the meaning of life or to deepen their understanding regarding the meaning of life. The 10 items are assessed on a scale from 1 - absolutely true to 7 - absolutely not true. The instrument showed good internal consistency: Cronbach's $\geq .80$ for both scales in the case of teenagers (Chen, Wang, He et al., 2021). In this study, we obtained $\alpha=.85$ for both subscales. $\chi^{2} / \mathrm{df}=3.01$; CFI $=.95$; RMSEA $=.081 ; \mathrm{SRMR}=.073 ; \mathrm{p}<.001$.

5. Inspiration Scale - IS (Thrash \& Elliot, 2003) measures inspiration and its dimensions: inspiration frequency (4 items) and inspiration intensity (4 items) on a scale of 1 - never to 7 - very often, with questions devised around the following definition of inspiration: "A breathing in or infusion of some idea, purpose, etc. into the mind; the suggestion, the awakening, or the creation of some feeling or impulse, especially of an exalted kind." Example of items: Something I encounter or experience inspires me a) How often does this happen? (Inspiration frequency); b) How deeply or strongly (in general)? (Inspiration intensity). Cronbach's $\alpha$ coefficients reported by the authors of the scales are $>.90$ in the case of several samples of undergraduates. IS correlates positively with extraversion, openness to experience and, mostly, with positive affect. In this study, we obtained Cronbach's $\alpha$ coefficient of high degree: $-\alpha$ 
$=.83-$ inspiration frequency, $\alpha=.82$ - inspiration intensity, and .89 - for the scale's total score. $\chi^{2} / \mathrm{df}=2.78 ; \mathrm{CFI}=.98 ; \mathrm{RMSEA}=.076 ; \mathrm{SRMR}=.0289 ; \mathrm{p}<.005$.

\subsection{Procedure}

A set of instruments was administered during the class, and it took students approximately 10 minutes to complete the questionnaire. The students were informed about the aim of the study beforehand, and they participated in it voluntarily, with no reward for this activity. Students filled out the form anonymously to control the results biasing as recommended by Podsakoff, Mackenzie, Lee et al. (2003).

\subsection{Data analysis}

Data analysis was conducted by means of statistics: 1) descriptive analysis in order to capture the traits of the analysed group, 2) correlational, focused on more complex interdimensional and regression interactions, and 3) regression, which shows the extent to which the analysed variables predict SWB. The SPSS 22 (IBM, New York, NY, USA) and JASP 0.14.1 software was used for analysis strategies.

\section{Results}

The state of subjective well-being was measured by adding the two components mentioned in the methodology paragraph, the affective one (positive affect and negative affect - SPANE) and the cognitive one (life satisfaction - LS-Si). Cronbach's $\alpha=.82$ and McDonald's $\omega=.83$.

The comparison with the standards of the instruments used and with other studies carried out on groups of students (Balgiu, 2019; Telef, 2015) helps us identify the characteristics of the analysed group using descriptive analysis (Table 1). For example, there are above-average values in the case of positive affect and moderate values in the case of negative affect. As for the meaning in life, it is much more probable that most students do not feel that their life has a meaning and a purpose, and they actively look for something or somebody that should give their life a meaning and a purpose (Steger, 2010).

Table 1 Descriptive statistics

\begin{tabular}{llcccccc}
\hline & \multicolumn{1}{c}{ Variables } & M & S.D. & Min. & Max. & $\alpha$ & $\omega$ \\
\hline LS-Si & Life satisfaction & 7.98 & 1.52 & 2 & 10 & - & - \\
SPANE & Positive affect & 23.02 & 4.25 & 9 & 30 & .86 & .88 \\
& Negative affect & 16.02 & 4.80 & 9 & 30 & .82 & .84 \\
& Ballance affect & 6.99 & 7.61 & -19 & 24 & .84 & .86 \\
SWB & Subjective well-being & 14.98 & 8.31 & -11 & 33 & .82 & .83 \\
& Inspiration frequency & 19.32 & 4.70 & 4 & 28 & .83 & .75 \\
IS & Inspiration intensity & 18.50 & 4.79 & 4 & 28 & .82 & .84 \\
& Total inspiration score & 37.82 & 8.85 & 4 & 28 & .89 & .89 \\
MLQ & Presence of meaning & 23.90 & 5.83 & 5 & 35 & .79 & .80 \\
& Search for meaning & 25.62 & 6.34 & 5 & 35 & .85 & .85 \\
GE-Si & Gratitude & 9.06 & 1.51 & 3 & 10 & - & - \\
\hline
\end{tabular}

Our option to resort to the second method of data analysis, namely the correlational analysis, was accounted for by our expectations to have results able to express the congruence of the variables we predicted in the constructed work hypothesis (Table 2). One can notice that there are positive moderate significant correlations between SWB and gratitude $(\mathrm{r}=.46 ; \mathrm{p}<.01)$ and the presence of meaning $(\mathrm{r}=.43 ; \mathrm{p}<.01)$, and weak correlations between SWB and inspiration frequency $(\mathrm{r}=.31 ; \mathrm{p}<.01)$, inspiration intensity $(\mathrm{r}=.20 ; \mathrm{p}<.01)$, and total inspiration score $(\mathrm{r}=.28 ; \mathrm{p}<.01)$.

There are negative correlations between SWB - the search for meaning, inspiration, life satisfaction, positive and negative effect. The search for meaning has positive weak correlations with the negative effect and negative correlations with the balance effect. 
Inspiration frequency correlates most strongly with positive affect $(\mathrm{r}=.35 ; \mathrm{p}<.01)$ and with the presence of meaning $(\mathrm{r}=.40 ; \mathrm{p}<.01)$, while intensity inspiration correlates more strongly with the presence of meaning.

Table 2 Intercorrelations between variables

\begin{tabular}{|c|c|c|c|c|c|c|c|c|c|c|}
\hline Vars. & 1 & 2 & 3 & 4 & 5 & 6 & 7 & 8 & 9 & 10 \\
\hline 1. LS & - & & & & & & & & & \\
\hline 2. PA & $.34 * *$ & - & & & & & & & & \\
\hline 3. NA & $-.22 * *$ & $-.43 * *$ & - & & & & & & & \\
\hline 4. BA & $.33 * *$ & $.82 * *$ & $-.86 * *$ & - & & & & & & \\
\hline 5. SWB & $.49 * *$ & $.82 * *$ & $-.84 * *$ & $.98 * *$ & - & & & & & \\
\hline 6. GR & $.61 * *$ & $.38 * *$ & $-.26 * *$ & $.37 * *$ & $.46 * *$ & - & & & & \\
\hline 7. PM & $.30 * *$ & $.41 * *$ & $-.28 * *$ & $.41 * *$ & $.43 * *$ & $.26 * *$ & - & & & \\
\hline 8. SM & -.05 & -.02 & $.17 * *$ & $-.12 *$ & $-.12 *$ & -.04 & .07 & - & & \\
\hline 9. IF & $.19 * *$ & $.35 * *$ & $-.17 * *$ & $.30 * *$ & $.31 * *$ & $.24 * *$ & $.40 * *$ & .05 & - & \\
\hline 10. II & $.15^{* *}$ & $.22 * *$ & -.10 & $.19 * *$ & $.20 * *$ & $.17 * *$ & $.32 * *$ & .09 & $.74 * *$ & - \\
\hline 11. TIS & $.19 * *$ & $.31 * *$ & $-.14 * *$ & $.26 * *$ & $.28 * *$ & $.22 * *$ & $.39 * *$ & .07 & $.93 * *$ & $.93 * *$ \\
\hline
\end{tabular}

Note: LS - Life satisfaction, PA - Positive affect, NA - Negative affect, BA - Ballance affect, SWB Subjective well-being, GR - Gratitude, PM - Presence of meaning, SM - search for meaning, IF Inspiration frequency, II - Inspiration intensity, TIS - Total inspiration score.

$* * \mathrm{p}<.01 ; * \mathrm{p}<.05$

In addition, if we take into consideration the effect size (the correlations in Cohen's terms), the moderate relation between SWB and gratitude is confirmed (r2=.29) and the presence of meaning $(\mathrm{r} 2=.18)$, as well as the weak correlation with the other variables ( $\mathrm{r} 2$ between .01 and .04). The result shows that students with a high level of SWB feel very grateful for whatever happens to them, and they consider that their lives are significant. The first hypothesis of the study was confirmed, and it demonstrates empirically that the increase of gratitude, of the frequency and of the depth of inspiration, as well as the early establishment of purposes result in the increase of SWB.

The second hypothesis was verified by using the hierarchical regression analysis. Before the analysis, we verified the condition of the standardized residue distribution, and the multicollinearity test was conducted by calculating the tolerance (the values of each independent variable should be greater than 1-R2 adjusted) and VIF (variance inflation factor) index. The homoscedasticity was verified by scatterplot. The tolerance values are between .80 and .98 , and the VIF is between 1.01 and $1.23<3.3$ the cutoff level recommended (Kock, 2015). The assumption of normality was calculated by the value of skewness and kurtosis. Because skewness is between -1.24 and .21 and kurtosis between -1.36 and .07 , it was accepted that the data are normally distributed. The Durbin-Watson coefficient $=1.97$. According to Field (2009), it takes values between 1 and 3.

After a series of regression analyses, we established the final model (Table 3). The latter's assessment shows the importance of gratitude for SWB. Thus, gratitude is one of the main predictors of SWB $(\beta=.34 ; p<.01)$, followed by the presence of meaning ( $\beta$ $=.30 ; \mathrm{p}<.01)$, and, to a smaller extent, by inspiration frequency $(\beta=.11 ; \mathrm{p}<.01)$. The explanatory power of the obtained model is significant $(\mathrm{R} 2=.34 ; \mathrm{F}=40.53 ; \mathrm{p}=.000)$, suggesting that the variables have an important association. Inspiration intensity is not a significant predictor of SWB.

Table 3 The analysis of hierarchical regression

\begin{tabular}{lccccccccc}
\hline Independent variables & $\mathrm{R}$ & $\mathrm{R}^{2}$ & $\begin{array}{c}\text { Adj } \\
. \mathrm{R}^{2}\end{array}$ & $\begin{array}{c}\text { Std. } \\
\text { error }\end{array}$ & $\beta$ & $\mathrm{t}$ & Sig. & $\mathrm{F}$ & Sig. \\
\hline Model & .58 & .34 & .33 & 6.77 & & -3.10 & & 40.53 & .000 \\
Gratitude & & & & & .34 & 7.13 & .000 & & \\
Presence of meaning & & & & & .30 & 5.93 & .000 & & \\
Search for meaning & & & & & -.13 & -2.89 & .000 & & \\
Inspiration frequency & & & & .11 & 2.35 & .021 & & \\
\hline
\end{tabular}


Predictors: gratitude, presence of meaning, search for meaning, inspiration frequency

Dependent variable: subjective well-being

\section{Discussions}

Results of the present study show that meaning in life, gratitude and inspiration are important correlates of subjective well-being. In this context, the strongest predictor of subjective well-being is gratitude. Focusing on positive events results in feeling satisfied with whatever happens in an individual's life, which leads to positive feelings. Individuals with high levels of gratitude are happier with their own life and experience positive emotional feelings more frequently than individuals with low levels of gratitude. Our findings are in line with research that has found that gratitude is the predictor which mostly accounted for subjective well-being (Sapmaz et al., 2016; Wood et al., 2010).

Presence of meaning and search for meaning are significant predictors, but the difference is that the search for meaning has a negative effect on subjective well-being. The result concerning the contribution of the two factors of meaning to subjective wellbeing is similar to that of other research which found that the presence of meaning and the search for meaning predict subjective well-being significantly, each with a different meaning: the presence of meaning affects subjective well-being positively, while the search for meaning predicts subjective well-being negatively (Cohen \& Cairns, 2012; Doğana et al., 2012). Other studies carried out on the general population find that the search for meaning correlates negatively with life satisfaction and subjective happiness, and positively with pessimism (Damásio \& Koller, 2015). It is highly probable that the inability to identify a purpose and the search for purpose generate negative feelings, pressure, and frustration. The association between the search for meaning and negative emotions had another level of intensity in the analysis of a sample of 500 Australian adults. The authors of the study concluded that individuals who evince low levels of presence of meaning and high levels of search for meaning have clinical levels of depression (Cohen \& Cairns, 2012). If we consider the intercorrelations between the items (MLQ and SPANE) it can be seen that the search for meaning correlates positively with sadness $(\mathrm{r}=.16 ; \mathrm{p}<.01)$ and fear $(\mathrm{r}=.21 ; \mathrm{p}<.01)$. The aspect would confirm the positive relationship between the search for meaning and negative mood.

The study highlights that inspiration frequency has a low significant effect on subjective well-being, while inspiration intensity is not a significant predictor. The finding suggests that the appearance of solutions in various situations and at various times leads to the well-being of individuals rather than the depth of solutions.

The presented results clearly show that inspiration is related to positive emotions. Although the study does not demonstrate the circular relation between inspiration and subjective well-being, the association between inspiration and positive affect makes us consider that inspiration produces positive emotion and it develops subjective wellbeing, implicitly, while in their turn, positive emotions show the presence of some favourable circumstances. We associate this idea with Broaden-and-Build theory (Fredrickson, 2013), which states that positive emotions extend the range of thinking patterns and action patterns, while negative emotions narrow it.

Students can preserve their subjective well-being if they establish aims, have a general positive attitude toward life and pay attention to internal/external stimuli which trigger positive emotions and, implicitly, nonconventional patterns of thinking and action. Results can be used in order to devise strategies for the development of the students' subjective well-being. Thus, journals of gratitude, identity exploration, goalsetting interventions, and intervention strategies that emphasize the importance of managing personal meaning can help students perform purposeful behaviour by understanding the significance of the events they go through. 


\section{References}

1. Ayyash-Abdo, H., \& Alamuddin, R. (2008). Predictors of subjective well-being among college youth in Lebanon. The Journal of Social Psychology, 147(3), 265-284.

2. Balgiu, B.A. (2019). Validation of the Scale of Positive and Negative Experience (SPANE) on a Romanian student sample. Revista de Psihologie, 65(3), 209-218.

3. Chen, M.-Y., Wang, K. E., Yang, R.-J., \& Liou, Y.-M. (2003). Adolescent health promotion scale: Development and psychometric testing. Public Health Nursing, 20, 104-110.

4. Chen, Q., Wang, X-Q., He, X-X., Ji, L-J., Liu, M-F., \& Ye, B-j. (2021). The relationship between search for meaning in life and symptoms of depression and anxiety: Key roles of the presence of meaning in life and life events among Chinese adolescents. Journal of Affective Disorders, 282(1), 545-553.

5. Cohen, K., \& Cairns, D. (2012). Is searching for meaning in life associated with reduced subjective well-being? Confirmation and possible moderators. Journal of Happiness Studies, 13(2), 313-331.

6. Damásio, B.F., \& Koller, S.H. (2015). Meaning in Life Questionnaire: Adaptation process and psychometric properties of the Brazilian version. Revista Latinoamericana de Psicología, 47(3), 185-195.

7. Datu, J.A.D. (2014). Forgiveness, gratitude, and subjective well being among Filipino adolescents. International Journal for the Advancement of Counselling, 36(3), 262-273.

8. Diener, E., Wirtz, D., Tov, W., Kim-Prieto, C., Choi. D., Oishi, S., \& Biswas-Diener, R. (2010). New measures of well-being: Flourishing and positive and negative feelings. Social Indicators Research, 39, 247-266.

9. Disabato, D.J., Kashdan, T.B., Short, J.L., \& Jarden A. (2017). What predicts positive life events that influence the course of depression? A longitudinal examination of gratitude and meaning in Life. Cognitive Therapy and Research, 41(3), 444-458.

10. Doğana, T., Sapmaz, F., Telb, F.D., Sapmaz, S., \& Temizel, S. (2012). Meaning in life and subjective well-being among Turkish university students. Procedia - Social and Behavioral Sciences, 55, 612-617.

11. Emmons, R. A., \& Mishra, A. (2011). Why gratitude enhances well-being. In K.M Sheldon, T.B. Kashdan, \& M.F. Steger (Eds.), Designing positive psychology: Taking stock and moving forward, pp. 458-485. New York: Oxford University Press.

12. Field, A. (2009). Discovering statistics using SPSS, London: Sage.

13. Fredrickson, B.L. (2013). Positive Emotions Broaden and Build. In P. Devine, \& A. Plant (Eds.), Advances in Experimental Social Psychology (pp. 1-53). Vol. 47, Burlington: Academic Press.

14. Galang, M.J., Magno C., Paterno V., \& Roldan A. (2011). Meaning in life, flow, and subjective well-being: A perspective on Filipino High School Students. Philippine Journal of Counseling Psychology, 13(1), 29-45.

15. Grigorescu, D. (2020). Curiosity, intrinsic motivation and the pleasure of knowledge, Journal of Educational Sciences \& Psychology, X(1), 16-23.

16. Hermaen, H., \& Bhutto, Z.H. (2020). Gratitude and Forgiveness as Predictors of Subjective WellBeing Among Young Adults in Pakistan, Pakistan Journal of Psychological Research, 35(4). 725-738.

17. Huebner, E.S. (1991). Initial development of the Students' Life Satisfaction Scale. School Psychology International, 12, 231-240.

18. Ionescu, D. (2017). Psychological well-being state and satisfaction of basic psychological needs as indicators of goal achievement - frantic role of neuroticism. Journal of Educational Sciences \& Psychology, VII(2), 75-86.

19. Jovanović, V. (2016). The validity of the Satisfaction with Life Scale in adolescents and a comparison with single-item life satisfaction measures: A preliminary study. Quality of Life Research, 25(12), 3173-3180.

20. Kashdan, T.B. (2013). Curios?: Descoperă ingredientul care-ţi lipseşte pentru o viaţă împlinită, [Curious?: Discover the missing ingredient to a fulfilling life], Bucureşti: Editura Trei.

21. Kock, N. (2015). Common method bias in PLS-SEM: a full colliniarity assessment approach, International Journal of e-Collaboration, 11(4), 1-10. 
22. Lin, C.C. (2014). A higher-order gratitude uniquely predicts subjective well-being: incremental validity above the personality and a single Gratitude. Social Indicator Research, 119, 909-924.

23. Lupano Perugini, M. L., de la Iglesia, G., Castro Solano, A., \& Keyes, C.L.M. (2017). The mental health continuum short form (MHC-SF) in the Argentinean Context: Confirmatory factor analysis and measurement invariance. Europe's Journal of Psychology, 13(1), 93-108.

24. Mayungbo, O.A., \& Iwuoha, C.C. (2020). Can university undergraduates improve their levels of happiness by being grateful and living a purposeful life? European Journal of Psychological Research, 7(2), 113-125.

25. Park, N., Park, M., \& Peterson, C. (2010). When is the search for meaning related to life satisfaction? Applied Psychology: Health and Well-being, 2(1), 1-13.

26. Podsakoff, P. M., MacKenzie, S. B., Lee, J. Y., \& Podsakoff, N. P. (2003). Common method biases in behavioral research: A critical review of the literature and recommended remedies. Journal of Applied Psychology, 88, 879-903.

27. Proctor, CA., Linley, P.A., \& Maltby, J. (2010). Very happy youths: benefits of very high life satisfaction among adolescents. Social Indicator Research, 98(3), 519-532.

28. Rand, K.L., Shanahan, M.L., Fischer, I. C., \& Fortney, S.K. (2020). Hope and optimism as predictors of academic performance and subjective well-being in college students. Learning and Individual Differences. 81, 101906

29. Robustelli, B. L., \& Whisman, M. A. (2018). Gratitude and life satisfaction in the United States and Japan. Journal of Happiness Studies, 19(1), 41-55.

30. Salvador-Ferrer, C. (2017). The relationship between gratitude and life satisfaction in a sample of Spanish university students: The moderation role of gender. Anales de psicología, 33(1), 114-119.

31. Sapmaz, F., Yıldırım, Topçuoğlu, P., Nalbant, D., \& Sızır, U. (2016). Gratitude, forgiveness and humility as predictors of subjective well-being among university students. International Online Journal of Educational Sciences, 8(1), 38-47.

32. Schindler, I. (2014). Relations of admiration and adoration with other emotions and well-being. Psychology of Well-being: Theory, Research, and Practice, 4(1), 1-23.

33. Steger, M.F. (2010). MLQ description scoring and feedback packet. Retrieved at http://www.michaelfsteger.com/wpcontent/uploads/2013/12/MLQ-description-scoring-andfeedback-packet.pdf

34. Steger, M.F., Frazier, P., Oishi, S., \& Kaler, M. (2006). The Meaning in Life Questionnaire: Assessing the presence of and search for meaning in life. Journal of Counseling Psychology, 53, 80-93

35. Steger, M.F., Kashdan, T. B., Sullivan, B. A., \& Lorentz, D. (2008). Understanding the search for meaning in life: Personality, cognitive style, and the dynamic between seeking and experiencing meaning. Journal of Personality, 76(2), 199-228.

36. Sun, P., \& Kong, F. (2013). Affective mediators of the influence of gratitude on life satisfaction in late adolescence. Social Indicator Research, 114(3), 1361-1369.

37. Telef, B.B. (2015). The positive and negative experience scale adaptation for Turkish university students. European Scientific Journal, 11(14), 49-59.

38. Trash T.M. (2007). Differentiation of the distributions of inspiration and positive affect across days of the week: An application of logistic multilevel modeling. In A. D. Ong \& M.H.M. van Dulmen (Eds.), Series in positive psychology. Oxford handbook of methods in positive psychology (p. 515-529). Oxford University Press.

39. Thrash, T.M., \& Elliot, A.J. (2003). Inspiration as a psychological construct. Journal of Personality and Social Psychology, 84(4), 871-889.

40. Thrash, T.M., \& Elliot, A. J. (2010). Inspiration and the promotion of well-being: tests of causality and mediation. Journal of Personality and Social Psychology, 98(3), 488-506.

41. Watson, D., Clark, L., \& Tellegen, A. (1988). Development and validation of brief measures of positive and negative affect: The PANAS scales. Journal of Personality and Social Psychology, 54, 1063-1070.

42. Wood, A.M., Froh, J.J., \& Geraghty, A.W.A. (2010). Gratitude and well-being: A review and theoretical integration. Clinical Psychology Review, 30, 890-905. 
43. Xiang, Y. \& Yuan, R. (2020). Why do people with high dispositional gratitude tend to experience high life satisfaction? A Broaden-and-Build theory perspective. Journal of Happiness Studies. Retrieved online at: file:///C:/Users/Windows/Downloads/XiangYuan2020_Article_WhyDoPeopleWithHighDisposition.pdf

44. Yoo, J. (2020). Gratitude and Subjective Well-Being among Koreans. International Journal of Environmental Research and Public Health, 17(22), 8467.

45. Yuchang, J.I.N., Mingcheng, H.E., \& Juny, L.I. (2016). The relationship between meaning in life and subjective well-being in China: A meta-analysis. Advances in Psychological Science, 24(12), $1854-1863$ 